\title{
FORMULATION OF A NATURAL FLAVOR ENHANCER BASED ON GLUTAMIC ACID AND STUDY OF SENSORY PROPERTIES
}

\author{
K.N. Wijayasekara ${ }^{1 *}$ and J. Wansapala ${ }^{1}$ \\ ${ }^{l}$ Department of Food Science and Technology, Faculty of Applied Sciences, University of Sri Jayewardenepura \\ Sri Lanka
}

\begin{abstract}
The main objective of this study was set as formulation of a natural and nutritious flavor enhancer using locally available ingredients with having umami taste as a replacement for Mono Sodium Glutamate (MSG). Mushrooms, Tomatoes, Carrots and Garlic were dehydrated and powdered prior to be used as ingredients. These ingredients were mixed according to Taguchi L8 design by changing the ratios to form eight different formulations. Eight different formulations were evaluated based on seven point hedonic scale. Formulations were added into dhal curry and sensory tests were carried out with dhal and bread. Thirty untrained panelists were contributed in the sensory evaluation and samples were analyzed for Appearance, Taste, Odor, Mouth feel and Overall Acceptability. Results were analyzed using MINITAB 14 for Kruskal Wallis non parametric analysis and Mann-Whitney test. Based on the results of two sensory evaluations, sample 767 formulae (Tomato 2: Mushroom 2: Carrot 1: Garlic 1) and 671 formulae (Tomato 2: Mushroom 1: Carrot 2: Garlic 2) were selected for the third evaluation where Formulae 671 showed the best results. Considering overall results of three sensory evaluations sample 671 was selected for the final product development. Out of all the sample, selected formulae (Tomato 2: Mushroom 1: Carrot 2: Garlic 2) contains the highest level of tomato, carrot and garlic along with the least amount of mushroom compared to other samples. Development of a flavor enhancer using natural ingredients as a substitute for MSG would be a great achievement as far as health and the natural taste of the food is concerned. In conclusion, sensory evaluations for eight different ratios of mixing above ingredients revealed that formulae 671 gave the best composition that could be a good replacer for MSG
\end{abstract}

Keywords: Mono Sodium Glutamate, Flavor, Sensory Evaluation

\section{Introduction}

Glutamate, one of the most common amino acids found in nature, is present in many proteins and peptides and most tissues. Glutamate is also produced in the body and binds with other amino acids to form a structural protein (Filer \& Stegink, 1994). When glutamate bounds to protein molecule, it is tasteless and does not provide umami taste to food. However, protein hydrolysis during fermentation, aging, ripening and heat cooking process will liberate free glutamate (Yoshida, 1998). Glutamate is a crucial component of the taste of cheese, seafoods, meat broths, and other foods (Ninomiya, 1998). It was also reported measured free glutamic acid, which present naturally in different foods, such as meat, poultry, seafood and vegetables. Konosu, Hayashi, and Yamaguchi (1987) showed that the characteristic tastes of many natural foods are reproduced by mixing amino acids, umami taste substances and salts in appropriate ratios.

The umami taste substances are contained abundantly in various foods, including vegetables (e.g., tomato, potato, Chinese cabbage, mushroom, carrot, soybean and green tea), seafood (e.g., fish, kelp, seaweed, oyster, 
prawn, crab, sea urchin, clam and scallop), meat (e.g., beef, pork and chicken) and cheese, and contribute greatly to the characteristic tastes of these foods (Kurihara, 2009). For example, the characteristic taste of snow crab meat is reproduced by mixing glycine, alanine, arginine, glutamate, IMP and salts in a particular. When the umami constituents were eliminated, the characteristic taste of the crab meat disappeared (Konosu et al., 1987). Thus, umami taste substances are essential for producing the unique taste of many natural foods ratio. The predominant flavor of mushrooms is the umami taste, also called the palatable taste or the perception of satisfaction, which is related to an overall flavor perception induced or enhanced by glutamate, and 50nucleotides (Bellisle, 1999).

The increase of free amino acids, sugars and organic acids during the ripening of vegetables, such as tomato contribute to the increase in flavor. For example, flavor maturation in ripening tomatoes has been related to the increase in their natural contents of free amino acids. During the ripening of cheese, proteins are broken down progressively into smaller polypeptides and individual amino acids (Weaver \& Kroger, 1978). Increases in these amino acids are generally recognized to be a reliable indicator of cheese ripening and contribute to the taste and texture of the cheese (Ramos, Caceres, Polo, Alonso, \& Juarez, 1987). Large increase in free amino acid content also occurs during the curing of ham, and glutamate is the most abundant free amino acid found in the final product (Cordoba, Rojas, Gonzalez, \& Barroso, 1994).Food additives which provide umami taste are categorized as a flavor emonopotassium glutamate, calcium diglutamate, monoammonium glutamate and magnesium diglutamate, as flavor enhancer (Codex, 1989). When glutamate is added to foods, it provides a flavoring function similar to naturally occurring free glutamate. For each food, there is an optimum glutamate concentration. Some foods, however, are not improved by the addition of glutamate, i.e., sweet foods in particular and perhaps some particularly bitter foods (Heyer, Taylor-Burds, Mitzelfelt, \& Delay, 2004). As for sweetness and saltiness, the optimal concentration of umami taste varies widely between individual consumers (Yeomans et al., 2008). Some consumers like it, again at varying concentrations, whereas some consumers seem indifferent to it, and some even dislike it.

Nevertheless, as the results of many studies clearly showed that most people are sensitive to its flavor-enhancing properties (Yeomans et al., 2008). Studies carried out among Europeans suggest that the optimal concentrations $(0.6-1.2 \%)$ tend to be somewhat higher than those reported by Asian consumers (Bellisle, 2008); this may be due to the relative deficit in awareness of the distinctive umami taste in Western consumers, or else to the fact that oral sensation varies with genetics and gene-environment interactions. Enhancer, which are salt of glutamate, namely monosodium glutamate, monoammonium glutamate, monopotasium glutamate, and ribonucleotides compounds, namely disodium 50-monoinosinate (IMP) and disodium 50-monoguanylate (GMP) (Ninomiya, 2001). Only the free form of glutamate, in its L-configuration presents flavor enhancing properties, and, for this reason, it is widely used as a flavor enhancer in the food industry (Bellisle, 1999; Populin et al., 2007). Codex Alimentarius categorized glutamate and its salts, monosodium glutamate monopotassium glutamate, calcium diglutamate, monoammonium glutamate and magnesium diglutamate, as flavor enhancer (Codex, 1989).

When glutamate is added to foods, it provides a flavoring function similar to naturally occurring free glutamate (Yamaguchi et al, 1971). For each food, there is an optimum glutamate concentration. Some foods, however, are not improved by the addition of glutamate, i.e., sweet foods in particular and perhaps some particularly bitter foods (Heyer, Taylor-Burds, Mitzelfelt, \& Delay, 2004). As for sweetness and saltiness, the optimal concentration of umami taste varies widely between individual consumers (Yeomans et al., 2008). Some consumers like it, again at varying concentrations, whereas some consumers seem indifferent to it, and some even dislike it.

Nevertheless, as the results of many studies clearly showed that most people are sensitive to its flavor-enhancing properties (Yeomans et al., 2008). Studies carried out among Europeans suggest that the optimal concentrations $(0.6-1.2 \%)$ tend to be somewhat higher than those reported by Asian consumers (Bellisle, 2008); this may be 
due to the relative deficit in awareness of the distinctive umami taste in Western consumers, or else to the fact that oral sensation varies with genetics and gene-environment interactions. Since early 1900s, monosodium Lglutamate (MSG) has been commercially manufactured for use as a flavor enhancer, and there is ample evidence that adding MSG to suitable foods increases their palatability (Bellisle et al., 1991; Yamaguchi \& Takahashi, 1984a,b). Such hedonic changes are probably partly mediated by changes in the sensory properties of the foods, including increase in richness, savourness and mouthfeel qualities (Fuke\& Shimizu, 1993; Prescott, 2001; Yamaguchi, 2000).

Glutamate is frequently added to processed foods and shaken onto foods during preparation, particularly in Asian cuisine (He et al., 2008). Based on psychometric studies on flavor of monosodium glutamate by Yamaguchi (1979), pure glutamate added has no effect on aroma of food. It can be added pure or as a hidden ingredient of yeast extracts or hydrolyzed proteins, both containing high percentages of glutamate (Hegenbart, 1998; Nagodawithana, 1992). Studies carried out among Europeans suggest that the optimal concentrations (0.6-1.2\%) tend to be somewhat higher than those reported by Asian consumers (Bellisle, 2008); this may be due to the relative deficit in awareness of the distinctive umami taste in Western consumers, or else to the fact that oral sensation varies with genetics and gene-environment interactions.

The use of excess amount of glutamate does not make the food taste better, but it actually worsens the taste. Generally, glutamate will work very well with salty or sour food. The optimum amount of added glutamate to enhance the taste of food is at $0.1-0.8 \%$ by weight. For instance, food of $500 \mathrm{~g}$ needs $0.5-4.0 \mathrm{~g}$ of glutamate to bring a good taste, which is the same as that of glutamate naturally found in general food. For example, protein from meat contains 11-22\% of glutamate, whereas plant protein shows $40 \%$ (IFT, 1987). The addition of glutamate at this amount can reduce the amount of added sodium chloride. It brings out the best natural flavors in food, working well in reduced-sodium and reduced-fat dishes and can reduce total sodium by 30-40\% without influencing palatability (Yamaguchi \& Takahashi, 1984).

\section{Methodology}

Mushrooms were washed and cut into small pieces and then they were blanched at $70^{\circ} \mathrm{C}$ for 15 seconds. Blanched mushroom were dried at drying oven at $60^{\circ} \mathrm{C}$ for 10 hours and then they were grind and sieved (by 200 $\mu \mathrm{m}$ mesh sieve) to obtain mushroom powder. Tomatoes were washed and cut blanched at $90^{\circ} \mathrm{C}$ water for 1 minute. Blanched tomatoes were dried at drying oven at $60^{\circ} \mathrm{C}$ for 12 hours and then they were grind and sieved (by $200 \mu \mathrm{m}$ mesh sieve) to obtain tomato powder. Carrots were washed, peeled and cut blanched in $90^{\circ} \mathrm{C}$ water for 5 minutes. Blanched carrots were dried at drying oven at $60^{\circ} \mathrm{C}$ for 10 hours and then they were grind and sieved (by $200 \mu \mathrm{m}$ mesh sieve) to obtain carrot powder. Garlic were peeled, washed and cut in to small pieces. They were dried at drying oven at $60^{\circ} \mathrm{C}$ for 8 hours and then they were grind and sieved (by $200 \mu \mathrm{m}$ mesh sieve) to obtain garlic powder. Mushrooms were washed and cut in to small pieces. Then they were dipped in following solutions for specific times. At $70^{\circ} \mathrm{C}$ water for 15 seconds, Cold water for 20 minutes, $2 \%$ salt solution for 5 minutes, $2 \%$ citric acid solution for 5 minutes, $2 \%$ ascorbic acid solution for 5 minutes.

Then treated mushrooms were dried at drying oven at $60^{\circ} \mathrm{C}$ for 10 hours and then they were grind and sieved (by $200 \mu \mathrm{m}$ mesh sieve) to obtain mushroom powder. After that best treatment were selected by checking odor and taste of mushroom powder. Mushroom powder, tomato powder, carrot powder and garlic powder were mixed as shown in table below. Here salt and garlic powder were taken as fixed value. Sensory properties were considered to obtain the best formula for the final product.

Table 01: Different ratios of raw materials mixed

\begin{tabular}{llllll}
\hline Formulation & $\begin{array}{l}\text { Tomato } \\
\text { powder }(\mathrm{g})\end{array}$ & $\begin{array}{l}\text { Mushroom } \\
\text { powder }(\mathrm{g})\end{array}$ & $\begin{array}{l}\text { Carrot } \\
\text { powder } \\
(\mathrm{g})\end{array}$ & $\begin{array}{l}\text { Garlic } \\
\text { powder }(\mathrm{g})\end{array}$ & $\begin{array}{l}\text { Iodide salt } \\
(\mathrm{g})\end{array}$ \\
\hline
\end{tabular}




\begin{tabular}{lllllll}
\hline Formula & 123 & 1 & 1 & 1 & 1 & 0.75 \\
Formula & 218 & 1 & 1 & 1 & 2 & 0.75 \\
Formula & 315 & 1 & 2 & 2 & 1 & 0.75 \\
Formula & 478 & 1 & 2 & 2 & 2 & 0.75 \\
Formula & 532 & 2 & 1 & 2 & 1 & 0.75 \\
Formula & 671 & 2 & 1 & 2 & 2 & 0.75 \\
Formula & 767 & 2 & 2 & 1 & 1 & 0.75 \\
Formula & 841 & 2 & 2 & 1 & 2 & 0.75 \\
\hline
\end{tabular}

The eight different formulations were introduced to the sensory panel to evaluate the best formulation for the final product. For the sensory evaluation, eight formulations were added into dhal curry and sensory test was carried out with dhal and bread. The untrained thirty panelists were participated to the sensory evaluation and the samples were given in three digit numbers as mentioned in the table 3.1. All samples were analyzed by sensory panel for the; Appearance, Taste, Odor, Mouth feels, Overall Acceptability Results of the sensory evaluation were analyzed using the computer software MINITAB 14. Kruskal Wallis non parametric analysis was used to data analysis for the sensory evaluation to determine whether any significant difference in the mean degree of liking scores exists between the samples. (Under the confidence interval of 95\%). Through the comparison the best or most preferred sample was selected as final product.

Three dhal samples were made using selected best formula and the commercial MSG (Aji-no-moto) and named as 671,767. The untrained thirty panelists were participated to the sensory evaluation and the Appearance, Taste, Odor, Mouth feel, Overall Acceptability were tested.

Results of the sensory evaluation were analyzed using the computer software MINITAB 14. Mann-Whitney test was used to data analysis for the sensory evaluation to determine whether any significant difference in the two population medians. (Under the confidence interval of 95\%). Hypothesis are taken as H0: $\mathrm{n}_{1}=\mathrm{n}_{2}$ versus H1: $\mathrm{n}_{1}$ $\neq \mathrm{n}_{2}$, where $\mathrm{n}$ is the population median.

\section{Results and Discussion}

Table 02: Results of the first sensory evaluation

\begin{tabular}{|l|l|l|l|l|l|l|l|}
\hline Sample & Color & Odor & Taste & Texture & Mouth Feel & Aftertaste & overall acceptability \\
\hline 123 & 5.3 & 4.7 & 5.05 & 5.1 & 5.1 & 4.95 & 5.05 \\
\hline 315 & 5.7 & 4.8 & 5.3 & 4.85 & 5.15 & 4.65 & 5.2 \\
\hline 532 & 5.8 & 5.05 & 5.4 & 5.1 & 5.25 & 5.15 & 5.45 \\
\hline 767 & 5.75 & 5.25 & 5.35 & 5.45 & 5.15 & 5.15 & 5.55 \\
\hline
\end{tabular}






Figure 01: Web diagram of the first sensory evaluation

According to the first sensory evaluation sample 767 obtained mean value of 5.8 for colour,5.05 for odor,5.4 for taste,5.1 for texture,5.25 for mouthfeel,5.15 for aftertaste,5.45 overall acceptability. Sample 767 was selected as the most acceptable product out of the first sensory evaluation.

Table 03: Results of the second sensory evaluation

\begin{tabular}{|l|l|l|l|l|l|l|l|}
\hline Sample & Color & Odor & Taste & Texture & Mouth Feel & Aftertaste & overall acceptability \\
\hline 218 & 4.40 & 3.77 & 3.40 & 4.33 & 3.93 & 3.77 & 3.70 \\
\hline 478 & 4.23 & 3.80 & 3.00 & 4.20 & 3.87 & 3.17 & 3.40 \\
\hline 671 & 4.30 & 4.30 & 4.00 & 4.07 & 4.77 & 4.33 & 4.50 \\
\hline 841 & 4.03 & 3.90 & 2.90 & 3.63 & 3.87 & 3.10 & 3.43 \\
\hline
\end{tabular}

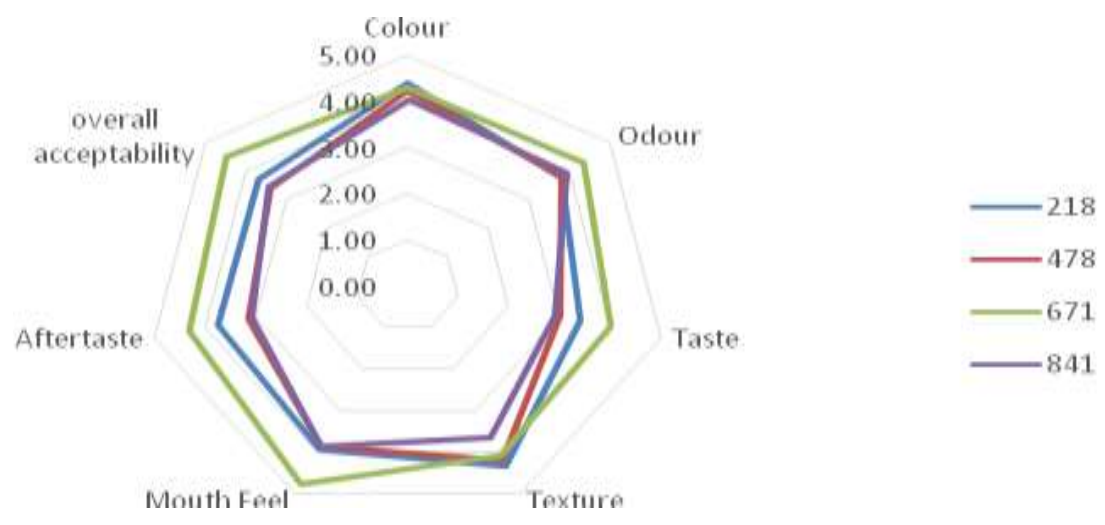

Figure 02: Web diagram of the second sensory evaluation 
According to the second sensory evaluation sample 671 obtained mean value of 4.30 for colour,4.30 for odor,4.00 for taste, 4.07 for texture, 4.77 for mouthfeel,4.33 for aftertaste, 4.50 for overall acceptability. Sample 671 was selected as the most acceptable product out of the second sensory evaluation.

Table 04: Results of the third sensory evaluation

\begin{tabular}{|l|l|l|l|l|l|}
\hline Sample & Color & Odor & Taste & $\begin{array}{l}\text { Mouth } \\
\text { Feel }\end{array}$ & $\begin{array}{l}\text { overall } \\
\text { acceptability }\end{array}$ \\
\hline 671 & 6.23 & 5.97 & 5.87 & 5.77 & 6.23 \\
\hline 767 & 6.20 & 5.77 & 5.87 & 5.57 & 5.97 \\
\hline
\end{tabular}
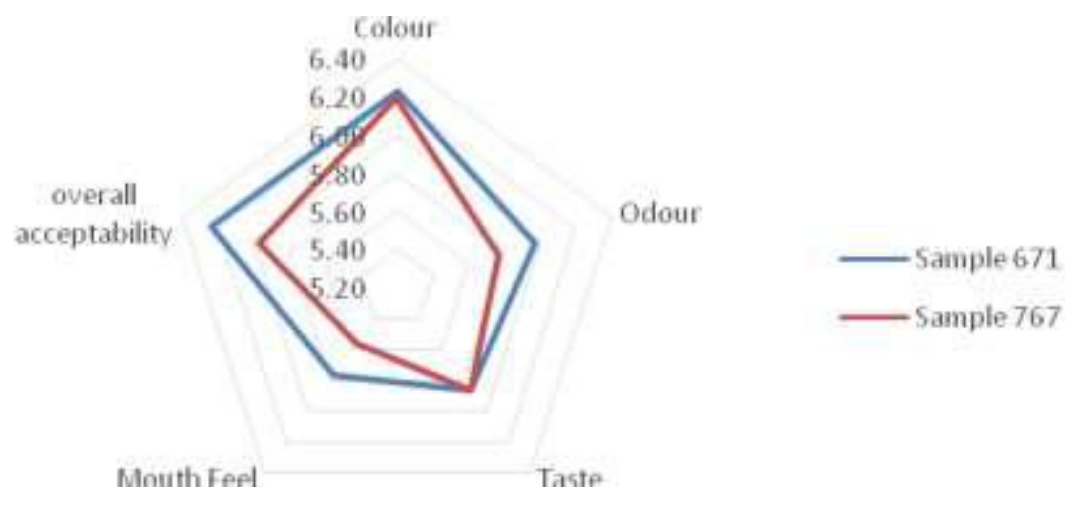

Figure 03: Web diagram of the third sensory evaluation

According to the third sensory evaluation selected sample 671 and sample 767 were evaluated. Sample 671obtained mean value of 6.23 for color, 5.97 for odor, 5.87 for taste, 5.77 for mouthfeel, 6.23 for overall acceptability. Sample 671 was selected as the most acceptable product out of the second sensory evaluation.

\section{Conclusion}

The eight different formulations were introduced to the sensory panel to evaluate the best formulation for the final product. For the sensory evaluation, eight formulations were added into dhal curry and sensory test was carried out with dhal and bread. The untrained thirty panelists were participated to the sensory evaluation. All samples were analyzed by sensory panel for the; Appearance, Taste, Odor, Mouth feels, Overall Acceptability Results of the sensory evaluation.

According to the results obtained from sensory evaluation powdered mushroom, tomato, carrot powder and garlic powder along with salt were used as ingredients for this study. After carrying out three sensory evaluations for eight different ratios of mixing above ingredients, formulae 671(mushroom: 1, tomato: 2, carrot: 2, garlic: 2) gave the best results to be chosen. 


\section{References}

Bellisle F, Monneuse MO, Chabert M, Lanteaume MT, Louis-Sylvestre J. Monosodium glutamate as a palatability enhancer in the European diet. Physiology and Behavior, 1991; 49:869-874.

Bellisle F. Experimental studies of food choices and palatability responses in European subjects exposed to the umami taste. Asia Pacific Journal of Clinical Nutrition. 2008; 17(S1):376-379.

Bellisle F. Glutamate and the umami taste. Sensory, metabolic, nutritional and behavioural considerations. A review of the literature published in the last 10 years. Neuroscience and Biobehavioral Reviews, 1999; 23:423438.

Bellisle F. Glutamate and the umami taste. Sensory, metabolic, nutritional and behavioural considerations. A review of the literature published in the last 10 years. Neuroscience and Biobehavioral Reviews, 1999; 23:423438.

Codex. Codex class names and the international numbering system for food additives. CAC/GL, 1989; 36:1-51.

Cordoba JJ, Rojas TA, Gonzalez CG, Barroso JV. Evolution of free amino acids and amines during ripening of Iberian cured ham. Journal of Agricultural and Food Chemistry. 1994; 42:2296-2301.

Filer LJ, Stegink LD. Report of the proceedings of the glutamate workshop. Critical Review in Food Science and Nutrition. 1994; 34(2):159-174.

Fuke S, Shimizu T. Sensory and preference aspects of umami. Trends in Food Science and Technology, 1993; 4:246-251.

He K, Zhao L, Daviglus ML, Dyer AR, Horn LV, Garside D et al. Association of monosodium glutamate intake with overweight in Chinese adults. The INTERMAP Study. Obesity, 2008; 16(8):1875-1880.

Hegenbart SL. Alternative enhancers. Food Product Design, 1998; 2:60-71.

Heyer BR, Taylor-Burds CC, Mitzelfelt JD, Delay ER. Monosodium glutamate and sweet taste. Discrimination between the tastes of sweet stimuli and glutamate in rats. Chemical Senses. 2004; 29:721-729.

Institute of Food Technology (IFT). Monosodium glutamate. Food Technology, 1987; 41:134-135.

Konosu S, Hayashi T, Yamaguchi K. Role of extractive components of boiled crab in producing the characteristic flavor. In L. J. Filer, S. Garattini, M. R. Kare, W. A, 1987.

Kurihara K. Glutamate. From discovery as a food flavor to role as a basic taste (umami). American Journal of Clinical Nutrition. 2009; 90:719S-722S.

Nagodawithana T. Yeast-derived flavors and flavor enhancers and their probable mode of action. Food Technology, 1992; 11:138-144.

Ninomiya K. An overview of recent research on MSG. Sensory applications and safety. Food Australia, 2001; 53:546-549.

Ninomiya K. Natural occurrence. Food Review International, 1998; 14:177-212.

Ramos M, Caceres I, Polo C, Alonso L, Juarez M. Effect of freezing on soluble nitrogen fraction of Cabrales Cheese. Food Chemistry. 1987; 24:271-278.

Weaver JC, Kroger M. Free amino acid and rheological measurements on hydrolyzed lactose cheddar cheese during ripening. Journal of Food Science. 1978; 43:579-583.

Yamaguchi S, Takahashi C. Interactions of monosodium glutamate and sodium chloride on saltiness and palatability of a clear soup. Journal of Food Science. 1984; 49(1):82-85.

Yamaguchi S, Yoshikawa T, Iikeda S, Ninomiya T. Measurement of the relative taste intensity of some l-amino acids and 5'-nucleotides. J Food Sci. 1971; 36:846-849.

Yamaguchi S. The umami taste. In: Food Taste Chemistry. Boudreau J. C., ed. ACS Symp. Series 115, American Chemical Society, Washington, DC, 1979, 33-51.

Yeomans MR, Gould NJ, Mobini S, Prescott J. Acquired flavor acceptance and intake facilitated by monosodium glutamate in humans. Physiology and Behavior, 2008; 93:958-966.

Yeomans MR, Gould NJ, Mobini S, Prescott J. Acquired flavor acceptance and intake facilitated by monosodium glutamate in humans. Physiology and Behavior, 2008; 93:958-966.

Yoshida Y. Umami taste and traditional seasoning. Food Review International, 1998; 14(2):213-246. 